\title{
EVALUATION OF ANTIFUNGAL PROPERTIES AGAINST THE PHYTOPATHOGENIC FUNGUS BOTRYTIS CINEREA OF ANTHOCYANIN RICH-EXTRACTS OBTAINED FROM GRAPE POMACES
}

\author{
LEONORA MENDOZA*A, MILENA COTORAS*A, MARCELA VIVANCOA ${ }^{*}$ BETTY MATSUHIRO ${ }^{4}$, \\ SIMONET TORRES ${ }^{B}$, MARÍA AGUIRRE .
}

${ }^{a}$ Universidad de Santiago de Chile, Facultad de Química y Biología, Av. Bernardo O'Higgins 3363, Estación Central Santiago, Chile. (Received: September 25, 2012 - Accepted: December 28, 2012)

\begin{abstract}
The anthocyanin content of grape pomace from different Chilean grape varieties (Vitis vinifera var. Cabernet Sauvignon, Carménère and Syrah) from two vineyards (Misiones de Rengo and Miguel Torres) was determined by the differential pH method and the anthocyanin perfile was characterized by HPLC. In all chromatograms, a major peak corresponding to malvidin-3-O-glucoside was observed. Also, the in vitro antifungal activity of these extracts against mycelia growth of the phytopathogenic fungus Botrytis cinerea was evaluated. The anthocyanin containing extract from Cabernet Sauvignon grape pomace of Misiones de Rengo vineyard was the most active. The extract from the same variety form Miguel Torres vineyard did not inhibit mycelia growth of $B$. cinerea. In general, the other extracts were less active against the fungus.
\end{abstract}

Keywords: Anthocyanins, antifungal activity, Botrytis cinerea, grape pomace.

\section{INTRODUCTION}

In the wine industry, a large amount of grape residues (grape pomace) are obtained and this residue consists mainly on skin residues, broken cells with pulp remains, stalks, and seeds ${ }^{1}$. Grape pomace composition varies depending on grape variety, climate and technology of vinification ${ }^{2}$ and it can be used as a rich source to obtain high-value products ${ }^{3-5}$.

In Chile, the vineyards throw away the grape pomace as waste when it is possible to obtain compounds of different structures with potential activities biological ${ }^{1,4,6,7}$.

Anthocyanins are attractive compounds to be extracted from grape pomace, due to their biological properties mainly as antioxidants or natural colorants ${ }^{8}$. Moreover, it has been reported that anthocyanin containing extracts present antifungal properties?.

Grey rot produced by Botrytis cinerea is an important disease of grapevines in temperate climates as in Chile and it causes extensive economic losses in grape production ${ }^{10}$. At the present time, $B$. cinerea is managed through of use of synthetic fungicide to avoid this important disease. These fungicides are becoming less accepted by wine industry because the increasing of resistant strains, public disapproval for their effect on human health and environmental pollution ${ }^{10}$. Therefore, wine industry is beginning to require alternative fungicides. A source of phenolic compounds with antifungal activity can be the grape pomaces because it has been reported that pomace of Gamayand Kalecik varieties inhibite growth in vivo and in vitro of Zygosaccahromyces rouxii and $Z$. bailii ${ }^{5}$. On the other hand, red and white wine phenolic extracts showed strong fungicidal activity against Candida albicans ${ }^{11,12}$. Moreover, phenolic compounds as quercetin, obtained from grape pomace have antifungal activity ${ }^{13}$

In this work, anthocyanin rich-extracts obtained from Chilean red grape pomace (Vitis vinifera var. Cabernet Sauvignon, Carménère, Syrah) were characterized and antifungal activity against $B$. cinerea of these extracts was evaluated.

\section{2.- EXPERIMENTAL}

\subsection{Materials}

Red grape pomaces (Vitis vinifera var. Cabernet Sauvignon, Carménère or Syrah) were obtained from Misiones de Rengo vineyard (Rengo, VI region, Chile) in May 2009. Also, red grape pomace residues (Vitis vinifera var. Cabernet Sauvignon or Syrah) obtained from Miguel Torres vineyard (Curicó, VII region, Chile) in May 2010, were used for this procedure. All solvents were reagent grade and/or HPLC grade (Merck, Darmstadt, Germany). All chemicals were reagent grade (Sigma, St. Louis, MO, USA).

2.2. Extraction of anthocyanins

Previous to extraction, the samples were freeze-dried milled to a particle size less than $0.5 \mathrm{~mm}$. Grape pomaces $(10 \mathrm{~g})$ of different varieties (Cabernet Sauvignon, Carménère or Syrah) were stirred with $100 \mathrm{~mL}$ of $1 \% \mathrm{HCl}$ in methanol at $4{ }^{\circ} \mathrm{C}$, and the mixture was centrifuged for $30 \mathrm{~min}$ at $4000 \mathrm{~g}$ and $25{ }^{\circ} \mathrm{C}$ employing a $4000 \mathrm{KS}-3000 \mathrm{P}$ (Kubota, Tokyo, Japan) centrifuge.
The pellet was extracted once with $100 \mathrm{~mL}$ of $1 \% \mathrm{HCl}$ in methanol. The extraction process was repeated four more times. The supernatants were collected and concentrated in vacuo $(50 \mathrm{~mL})$, and sequentially washed with $50 \mathrm{~mL}$ of $\mathrm{n}$-hexane, chloroform, and ethyl acetate. The aqueous solution was concentrated in vacuo, dissolved in distilled water and analysed by HPLC.

2.3 Colorimetric analysis of anthocyanins

Anthocyanin content in extracts was determined by the differential $\mathrm{pH}$ method, according to Wang and $\mathrm{Lin}^{14}$. Absorbance was measured at 700 and $520 \mathrm{~nm}$ in a Genesys 5 (ThermoSpectronic, Waltham, MA, USA) spectrophotometer, at $\mathrm{pH} 1.0$ and 3.5. Anthocyanins were quantified as malvidin-3-O-glucoside using the extinction coefficient $(\varepsilon=28000)$.

2.4 High performance liquid chromatography $(H P L C)$ analysis

For the HPLC analysis a Waters 600 HPLC chromatograph (Waters, Mildford, MA, USA) equipped with a Waters 2990 diode array detector, and a Symmetry C-18 (5 um) (Waters, Milford, MA, USA) column ( 3.9 x $150 \mathrm{~mm}$ ) was used. The solvent system consisted of $1 \%$ aqueous formic acid (A) and $1 \%$ formic acid in acetonitrile (B). The initial composition of the mobile phase was $95 \% \mathrm{~A}$ and $5 \% \mathrm{~B}$. With linear gradients the composition changed to $75 \%$ $\mathrm{A}$ and $25 \% \mathrm{~B}$ within $45 \mathrm{~min}$, and $50 \% \mathrm{~A}$ and $50 \% \mathrm{~B}$ within $60 \mathrm{~min}$. The flow rate was $0.8 \mathrm{~mL} / \mathrm{min}$.

2.5 Fungal isolate and culture conditions

In this study B. cinerea strain G29 was used. This strain was originally isolated from naturally infected grapes (Vitis vinifera $)^{15}$ and it was maintained on malt-yeast extract agar slants $(2 \%(\mathrm{w} / \mathrm{v})$ malt extract, $0.2 \%(\mathrm{w} / \mathrm{v})$ yeast extract and $1.5 \%(\mathrm{w} / \mathrm{v})$ agar) at $4{ }^{\circ} \mathrm{C}$. The fungus was grown in the dark on malt-yeast extract agar medium or soft agar medium $(2 \%(\mathrm{w} / \mathrm{v})$ malt extract, $0.2 \%(\mathrm{w} / \mathrm{v})$ yeast extract and $0.6 \%(\mathrm{w} / \mathrm{v})$ agar $)$.

2.6 Fungitoxicity activity

The fungitoxicity on mycelial growth of $B$. cinerea of different anthocyanin extracts was assessed in vitro using the radial growth test on malt-yeast extract agar $^{16}$. Anthocynin extracts dissolved in $0.2 \mathrm{M}$ sodium acetate buffer, $\mathrm{pH} 4.9$ at different concentrations were added to malt-yeast extract agar medium.

Petri dishes containing culture medium with anthocyanin extracts or 0.2 $\mathrm{M}$ sodium acetate buffer $\mathrm{pH} 4.9$ at the same concentrations as treatments were inoculated with $0.5 \mathrm{~cm}$ of agar disk containing $B$. cinerea fresh mycelium and incubated at $22{ }^{\circ} \mathrm{C}$ for 5 days. The radial growth of the fungus was measured daily. After 72 hours of incubation the inhibition percentages relative to the control were calculated. Results of antifungal effect were expressed as $\mathrm{IC}_{50}$ (concentration that reduced mycelial growth by $50 \%$ ) determined by regressing the inhibition of radial growth values (percent control) at different extract or compound concentrations.

All experiments were done at least in triplicate. The commercial fungicide, iprodione, was used as control. This compound was added to culture plates dissolved in methanol at different concentrations. In this case, inhibition percentages were calculated relative to control with methanol at the same concentration as treatments.

Analysis of the stability of anthocyanins in sodium acetate buffer at $\mathrm{pH}$ 4.9 was performed by HPLC and subsequent comparison with anthocyanin extracts dissolved at $\mathrm{pH} 3$ (results not shown). 


\section{RESULTS AND DISCUSSION}

3.1 Extractions and characterization of anthocyanins from grape pomace extracts

It has largely been reported that the extraction method affects the anthocyanin content of the extracts ${ }^{17-19}$. Metivier ${ }^{17}$ demonstrated that the rate and degree of extraction of anthocyanins from grape pomace depends on factors such as solvent (ethanol, methanol, water), and acid $(\mathrm{HCl}$, citric, tartaric, formic, acetic, propionic). In this work, methanol and $\mathrm{HCl}$ were used to extract anthocyanins from grape pomace because it has been reported that with this method good yields in extraction of anthocyanins were obtained ${ }^{19}$. The total content of anthocyanins and oligomeric anthocyanins in extracts obtained from different grape pomace varieties was determined by differential $\mathrm{pH}$ method. It was quantified in $\mathrm{mg}$ of anthocyanins and expressed as malvidin3-O-glucoside by $100 \mathrm{~g}$ of grape pomace (Table 1).

Table 1: Content of anthocyanins in red wine grape pomace varieties.

\begin{tabular}{|c|c|}
\hline Varieties* & Anthocyanins total $(\mathrm{mg} / 100 \mathrm{~g})^{* *}$ \\
\hline Carménère (MR) & $42.99 \pm 8.22$ \\
\hline Syrah (MR) & $20.74 \pm 0.02$ \\
\hline Cabernet sauvignon (MR) & $23.04 \pm 1.74$ \\
\hline Syrah (MT) & $70.86 \pm 5.71$ \\
\hline Cabernet sauvignon (MT) & $16.98 \pm 2.45$ \\
\hline
\end{tabular}

*Varieties MR: Misiones de Rengo Vineyard; MT: Miguel Torres Vineyard

**mg of anthocyanins expressed as malvidin-3-O-glucoside by $100 \mathrm{~g}$ of grape pomace

Extract obtained from Syrah variety of Miguel Torres Vineyard presented the highest concentration of total anthocyanins. A difference in the total anthocyanin contents can be observed when extracts obtained from Cabernet Sauvignon grape pomace of different vineyard are compared. Extract obtained from Miguel Torres vineyard had lower anthocyanin content than the extract obtained from Misiones de Rengo vineyard. Therefore, it can be concluded that the anthocyanin content depends of grape variety, environmental factors as location and climate or the technology of wine making. Rodríguez Montealegre ${ }^{20}$ postulated that the differences reported in the phenolic compound content can be attributable to climatic differences. On the other hand, Kammerer ${ }^{21}$ reported that these differences depend on cultivar and vintage. Also, it has been shown that the wine processing technique affects the phenolic compound content from grape pomace ${ }^{2,22}$.

The analysis of the anthocyanin-containing extracts was carried out by HPLC with diode array detection. HPLC analysis of the extracts revealed the presence of several peak ( 3 to 8 in the different extract), with a major signal, in all extracts, between 28-29 min. Figures 1A and 1B show chromatogram of Carménère (MR) and Syrah (MR) extracts.

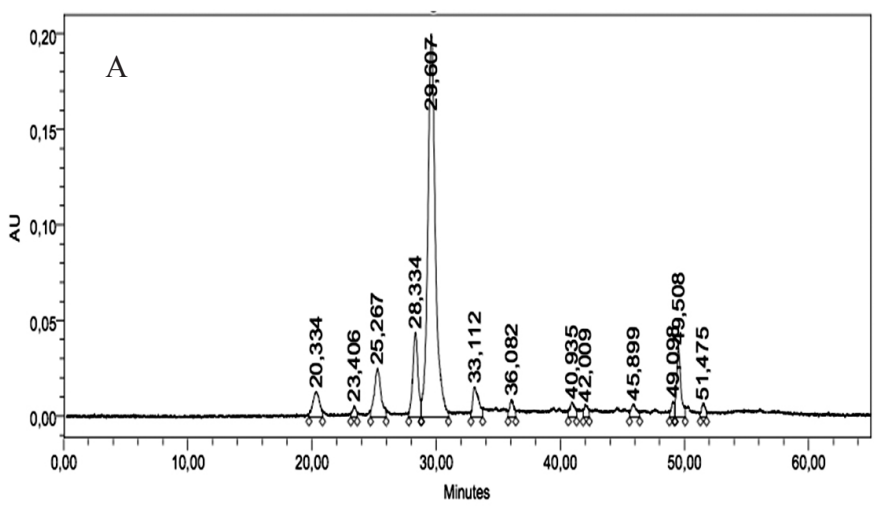

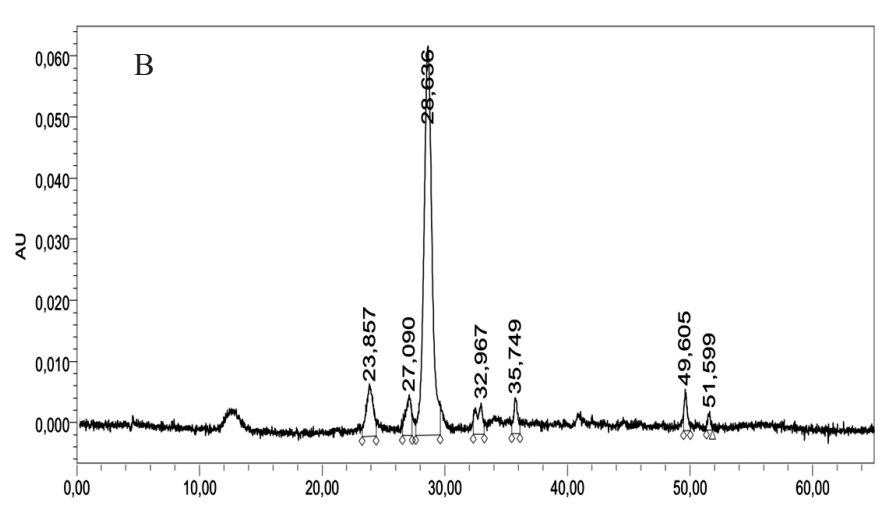

Figure 1. A HPLC elution profiles recorded at $520 \mathrm{~nm}$ of Carménère extracts (MR) from grape pomace (A) and Syrah extracts (MR) from grape pomace (B).

By comparison of the results with those reported in the literature ${ }^{19}$ where HPLC coupled to electrospray ionization-mass spectrometry in wine, grape and raspberry extracts was used, it was determined that the principal signal corresponded to malvidin-3-O-glucoside (Figure 2) The others signal could be the polymeric anthocyanins described to vintage wine ${ }^{23,24}$.<smiles>COc1cc(-c2[o+]c3cc(O)cc(O)c3cc2O[C@@H]2O[C@H]3C(O)[C@H](O)[C@H](O2)[C@H](O)[C@H]3O)cc(OC)c1O</smiles>

Figure 2. Chemical structure of the Malvidin-3-O-glucoside.

\subsection{Antifungal activity}

The effect of the extracts against mycelia growth of $B$. cinerea is shown in table 2. As control the effect of the commercial fungicide, iprodione, on $B$. cinerea mycelial growth was determined and this fungicide presented an IC50 value of $4.9 \mathrm{ppm}$. In general, the extracts with exception of Miguel Torres vineyard presented an antifungal activity similar to the fungicide. The extract obtained from Cabernet Sauvignon grape pomace of Misiones de Rengo Vineyard was the more active. Surprisingly the same extract of Miguel Torres vineyard did not inhibit mycelia growth of $B$. cinerea. This extract also showed the lowest content of total anthocyanins (Table 1). There are few reports of the antifungal effect of anthocyanins against $B$. cinerea. In that sense, Schaefer ${ }^{9}$ reported that extracts containing anthocyanins decreased fruit-rot in grape varieties infected with $B$. cinerea. These extracts contained Malvidin-3-Oglucoside among other anthocyanins identified in grape pomace'. Otherwise, quercetin-3-galactoside, cyanidin-3-glucoside, pelargonidin-3-glucoside, were evaluated in vitro for their antifungal activities and mode of action on this fungus. Inhibitory effects were found for all the anthocyanins, but varied at different fungal developmental stages. Quercetin-3-galactoside showed linear inhibitory effects on germ tube elongation. Cyanidin-3-glucoside and pelargonidin-3-glucoside provided effective control on the fungi as concentrations increased ${ }^{25}$. 
Table 2: Effect of anthocyanin extract on mycelia growth of $\boldsymbol{B}$. cinerea

\begin{tabular}{|c|c|}
\hline Varieties* & $\mathrm{IC}_{50} \mu \mathrm{g} / \mathrm{mL}^{* *}$ \\
\hline Cabernet Sauvignon (MR) & $1.45 \pm 0.18$ \\
Syrah (MR) & $2.83 \pm 0.11$ \\
Carménère (MR) & $3.72 \pm 0.14$ \\
Cabernet sauvignon (MT) & N.D. \\
Syrah (MT) & $5.50 \pm 0.09$ \\
\hline
\end{tabular}

*Varieties: MR: Misiones de Rengo Vineyard and MT: Miguel Torres Vineyard

** $\mathrm{IC}_{50}$ values were calculated at $72 \mathrm{~h}$ of incubation.

N.D.: not detected antifungal activity

\section{CONCLUSIONS}

Syrah extract grape pomace of Misiones de Rengo Vineyard contains more anthocyanins than the other varieties analyzed. In all varieties of grape pomace was found simple and oligomeric anthocyanis and the principal anthocyanin was identified as malvidin-3-O-glucoside. The evaluation antifungal against $B$. cinerea of anthocyanin containing grape pomace extracts showed that those from Cabernet Sauvignon of Misiones de Rengo Vineyard presented the highest antifungal activity. These results would indicate that there would be a correlation between the total content of anthocyanins from grape pomace of different varieties and antifungal activity.

\section{ACKNOWLEDGEMENTS}

This research was supported by the FONDECYT Grants N 1090723 1120071 and the Departamento de Investigaciones Científicas y Tecnológicas (DICYT) of the Universidad de Santiago de Chile.

\section{REFERENCES}

1.- $\quad$ A. Meyer, M. Signe, S. Jepsen, N. Sørensen J. Agric. Food Chem.46, 7, (1998)

2.- A. Schieber, F. C. Stintzing, R. Carle, Trends Food Sci. Technol. , 12, 401, (2001)

3.- I.S. Arvanitoyannis, D. Ladas, A . Mavromatis, International Journal of Food Science \& Technology. 41, 475, (2006)

4.- I. Rockenbach, E. Rodrigues, L. V. Gonzaga, V. Caliari, M. I. Genovese, A. de Souza, S. Gonçalves, Roseane Fett Food Chemistry. 127, 174, (2011)

5.- O. Sagdic, I. Ozturk, G. Ozkan, H. Yetim, L. Ekici, M. Yilmaz, Food Chemistry. 126, 1749 (2011)
6.- K.N. Chidambara, R.P. Singh, G.K. Jayaprakasha, Journal of Agricultural and Food Chemistry. 50, 5909, (2002)

7.- A.M. González-Paramás, S. Esteban-Ruano, C. Santos-Buelga, S. de Pascual-Teresa, J.C. Rivas-Gonzalo Journal of Agricultural and Food Chemistry. 52, 234, (2003)

8.- J.M. Kong, L.S. Chia, N.K. Goh, T.F. Chia, R. Brouillard, Phytochemistry. 64, 923, (2003)

9- H.M. Schaefer, M. Rentzsch, M. Breuer, Natural Product Communications 3, 1267, (2008)

10.- M.A. Jacometti, S.D. Wratten, M. Walter Australian Journal of Grape and Wine Research. 16, 154, (2010)

11.- H.J. Jung, D.G. Lee, Journal of Microbiology and Biotechnology. 17, $1324,(2007)$

12.- C. Papadopoulou, K. Soulti, I. Rousis, Food Technology and Biotechnology. 43, 41, (2005)

13.- H.K. Sandhar, B. Kumar, S. Prasher, P. Tiwari, M. Salhan, P. Sharma Internationale Pharmaceutica Sciencia. 1, 25 (2011)

14.- S. Y. Wang, H.S. Lin Journal of Agricultural and Food Chemistry. 48, $140,(2000)$

15.- G. Muñoz, P. Hinrichsen, Y. Brygoo, T. Giraud, Mycological Research. 106, 594, (2002)

16.- L. Mendoza, B. Modak, R. Torres, M. Cotoras. Journal Chilean Chemistry Society, 53, 1436, (2008)

17.- R. P. Metivier, F. J. Francis, F. M. Clydesdale, Journal of Food Science. 45, 1099, (1980)

18.- D. Kammerer, J. Gajdos Kljusuric, R. Carle, A . Schieber. European Food Research and Technology. 220, 431, (2005)

19.- M. J. Aguirre, Y. Chen, M. Isaacs, B. Matsuhiro, L. Mendoza, S. Torres, Food Chemistry. 121, 44, (2010)

20.- R. Rodríguez Montealegre, R. Romero Peces, Chacón, J.L. Vozmediano, J. Martínez Gascueña, E. García Romero, Journal of Food Composition and Analysis, 19, 687, (2006)

21.- D. Kammerer, A. Claus, R. Carle, A. Schieber, Journal of Agricultural and Food Chemistry. 52, 4360, (2004)

22.- E. Gómez-Plaza, A. Miñano, J.M. López-Roca, Food Chemistry. 97, 87, (2006)

23.- J. Oliveira, C. Santos-Buelga, M.S. Silva, V. de Freitas, N. Mateus. Analytica Chimica Acta 563, 2, (2006)

24.- C. Alcalde-Eon, M.T. Escribano-Bailón, C. Santos-Buelga, J. RivasGonzalo Journal Mass Spectrometry. 42, 735, (2007)

25.- S. Tao, S. Zhang, R. Tsao, M.T. Charles, R. Yang, S. Khanizadeh, Archives of Phytopathology and Plant Protection. 43, 1564, (2010). 